Online Submissions: http:/ / www.wjgnet.com/1949-8470office wjr@wjgnet.com

doi:10.4329/wjr.v2.i3.97

World J Radiol 2010 March 28; 2(3): 97-102

ISSN 1949-8470 (online)

(C) 2010 Baishideng. All rights reserved.

TOPIC HIGHLIGHT

Hui-Xiong Xu, MD, PhD, Series Editor

\title{
Contrast-enhanced ultrasound of the pancreas
}

\author{
Mirko D’Onofrio, Anna Gallotti, Francesco Principe, Roberto Pozzi Mucelli
}

Mirko D’Onofrio, Anna Gallotti, Francesco Principe, Roberto Pozzi Mucelli, Department of Radiology, University Hospital G.B. Rossi, University of Verona, Verona 37134, Italy Author contributions: D'Onofrio M, Gallotti A, Principe F and Pozzi Mucelli R contributed equally to this work; D'Onofrio $\mathrm{M}$ and Gallotti A designed, performed and wrote the paper; Principe F organized the paper; Pozzi Mucelli R revised the manuscript.

Correspondence to: Mirko D'Onofrio, MD, Assistant Professor, Department of Radiology, University Hospital G.B. Rossi, University of Verona, Piazzale L.A. Scuro 10, Verona 37134,

Italy.mirko.donofrio@univr.it

Telephone: +39-45-8124140 Fax: +39-45-8277808

Received: February 12, 2010 Revised: March 8, 2010

Accepted: March 15, 2010

Published online: March 28, 2010

\section{Abstract}

The introduction of contrast-enhanced ultrasonography (CEUS) has led to major improvements in the diagnostic capabilities of ultrasound (US). The innovative use of CEUS for study of the pancreas has created the need for a definition of the most frequent dynamic features of solid and cystic masses. CEUS is less expensive compared to computed tomography and magnetic resonance imaging and is able to significantly improve the accuracy of US, allowing better characterization and staging of pancreatic pathologies.

\section{(c) 2010 Baishideng. All rights reserved.}

Key words: Contrast-enhanced ultrasonography; Ultrasound; Pancreatic diseases

Peer reviewer: Kenneth Coenegrachts, MD, PhD, Department of Radiology, AZ St.-Jan AV, Ruddershove 10, B-8000 Bruges, Belgium

D’Onofrio M, Gallotti A, Principe F, Pozzi Mucelli R. Contrastenhanced ultrasound of the pancreas. World J Radiol 2010; 2(3): 97-102 Available from: URL: http://www.wjgnet. com/1949-8470/full/v2/i3/97.htm DOI: http://dx.doi. org/10.4329/wjr.v2.i3.97

\section{INTRODUCTION}

Ultrasound (US) is often the first mode of examination in patients with pancreatic disease. The introduction of contrast-enhanced ultrasonography (CEUS) has led to great improvements in the diagnostic capabilities of $\mathrm{US}^{[1]}$.

CEUS takes advantage of its special features: the high contrast and spatial resolution, the use of a bloodpool microbubble contrast medium and the real-time, dynamic evaluation of tumor enhancement, filtering the background tissue signals ${ }^{[1-3]}$. CEUS is a sensitive imaging method for evaluating the vascularization of pancreatic lesions both solid and cystic ${ }^{[2-7]}$. The innovative use of CEUS for pancreatic study creates the need for a definition of the most frequent dynamic features of solid and cystic masses.

To overcome subjectivity, the use of quantification software could be suggested for the characterization of pancreatic lesions during CEUS study, as recently reported in the literature ${ }^{[8]}$. Its high capability in showing tumoral microcirculation also makes CEUS accurate in the study of neoangiogenesis ${ }^{[9]}$. Interest in the use of CEUS for noninvasive prognostic stratification of pancreatic adenocarcinoma and for the evaluation of chemotherapeutic effects is documented in the literature ${ }^{[10-13]}$.

CEUS is less expensive compared to computed tomography (CT) and magnetic resonance imaging (MRI) and can also be used in patients with renal failure ${ }^{[1,14]}$. CEUS is able to significantly improve the accuracy of US, allowing a better characterization and staging of pancreatic pathologies ${ }^{[2-7]}$.

\section{TECHNICAL BACKGROUND AND} CONTRAST MEDIA

CEUS is the only imaging method that allows a real- 
time evaluation of the enhancement during the dynamic phases. Harmonic microbubble (MB)-specific imaging with a low acoustic US pressure (Mechanical index, < 0.2 ) is required for a dynamic CEUS examination. All the background tissue signals are filtered and the vascular enhancement signals are only related to the harmonic responses of the MBs. A $2.4 \mathrm{~mL}$ bolus of second-generation contrast agent, constituted by sulphur hexafluoride filled microbubbles with a phospholipid peripheral shell (SonoVue $^{\circledR}$, Bracco, Milan, Italy), is injected i.v. followed by a $5 \mathrm{~mL}$ bolus of saline solution. A real-time evaluation of the enhancement is possible, maintaining the same scanning frame rate as in the previous conventional B-mode examination. Dynamic observation of the contrast-enhanced phases (arterial, portal/venous and late phases) begins immediately after the injection of the microbubbles ${ }^{[15]}$.

These typical features of CEUS make this method very accurate in perfusion studies, allowing the visualization of the pancreatic lesion microvasculature ${ }^{[2,7]}$. Some major limitations are the occasionally restricted image resolution of deep regions and the poor sonographic visualization of the gland due to overlying abdominal gas or to large amounts of abdominal fat $\mathrm{f}^{[1,2]}$.

\section{CLINICAL APPLICATIONS}

\section{Inflammatory diseases}

Acute pancreatitis: Acute focal pancreatitis, even when supported by clinical data, can cause problems of differential diagnosis in respect to neoplastic lesions ${ }^{[16,17]}$. A mild acute focal pancreatitis appears as a homogeneously hypoechoic focal enlargement of the gland in conventional US ${ }^{[16,17]}$, and hypervascularized after the administration of contrast agent ${ }^{[17]}$, with different degree of enhancement, resulting in an increased echogenicity in the dynamic phases.

In severe acute pancreatitis, CEUS may improve the detection and delimitation of the necrotic areas, which appear completely avascular ${ }^{[17]}$. Unfortunately, in the literature there are no studies comparing CEUS with CT or MRI in the evaluation and follow-up of acute pancreatitis. At this moment, CT remains more effective than CEUS, in particular in grading the stage of the diseas $\mathrm{e}^{[18]}$.

Pseudocysts: Pseudocysts can be sequelae of severe acute pancreatitis or can occur in chronic pancreatitis ${ }^{[18]}$. Characterized by a fibrous wall without an epithelial lining ${ }^{[19]}$, pseudocysts must be differentiated from pancreatic cystic tumors, especially mucinous cystadenomas (MCAs), as they require completely different therapeutic approach$\mathrm{es}^{[19]}$. CEUS has a crucial role in differential diagnosis of pseudocysts and pancreatic cystic tumors, by better evaluating the micro-vascularization of the intralesional inclusions. Even if characterized by a corpuscular and inhomogeneous content in conventional US, pseudocysts are always completely avascular, becoming homogeneously anechoic in CEUS dynamic examination ${ }^{[2]}$.

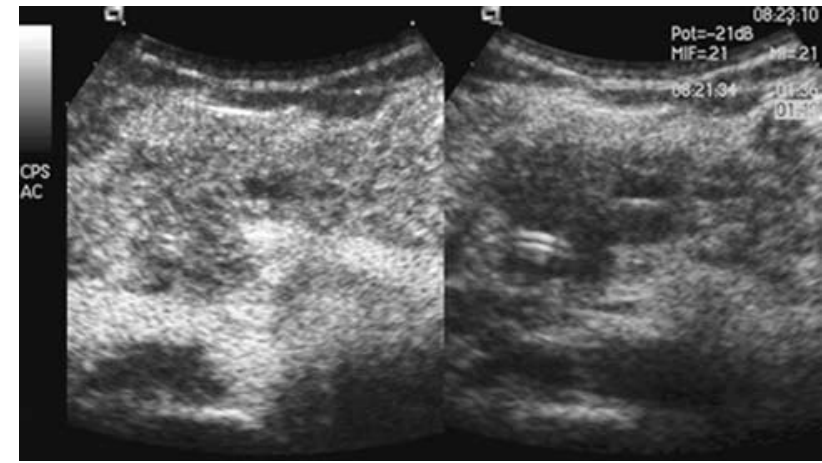

Figure 1 Focal autoimmune pancreatitis. The pancreatic head mass is hypoechoic in conventional ultrasound (US) (right side of the split-screen) and inhomogeneously isovascular in contrast-enhanced US (CEUS) (left side of the split-screen).

Mass forming chronic pancreatitis: Mass-forming chronic pancreatitis usually occurs in patients with a history of chronic pancreatitis ${ }^{[20]}$ and must be differentiated from pancreatic ductal adenocarcinoma ${ }^{[2,7,21]}$, although they are both hypoechoic in conventional US. In CEUS, a mass-forming chronic pancreatitis shows 'parenchymographic' enhancement, characterized by an enhancement pattern always comparable to that of the surrounding pancreatic parenchyma. However, in long-standing chronic inflammatory processes, inhomogeneous hypovascularization of the lesion may be observed, probably owing to the presence of a large amount of fibrosis, and the differential diagnosis becomes more difficult ${ }^{[2,7,21]}$.

Autoimmune pancreatitis: Autoimmune pancreatitis is a particular type of chronic pancreatitis. Characterized by periductal flogosis, mainly sustained by lymphocytic infiltration, with evolution to fibrosis, this pancreatic pathology has a recent pathological definition ${ }^{[22]}$. The US features resemble those of focal pancreatitis, even if autoimmune pancreatitis more frequently involves the entire gland, with a global enlargement of the pancreas. In all cases, in conventional US the echogenicity is typically markedly reduced and the main pancreatic duct compressed. After the administration of contrast agent, autoimmune pancreatitis shows inhomogeneous a fair, often moderate to marked, enhancement usually followed by a slow washout. These features are related to the thinning of the glandular vessels due to thick lymphocytic infiltration and fibrosis.

CEUS findings may be especially useful in the study of focal forms of autoimmune chronic pancreatitis (Figure 1), in which differential diagnosis in respect to ductal adenocarcinoma is a priority ${ }^{[21,23]}$.

\section{Solid neoplasms}

Ductal adenocarcinoma: Pancreatic tumors are classified according to their histological type and grade in the WHO classification ${ }^{[24]}$. Ductal adenocarcinoma comprises between $80 \%$ and $90 \%$ of all exocrine tumors of the pancreas. It usually presents as a solid mass with infiltra- 


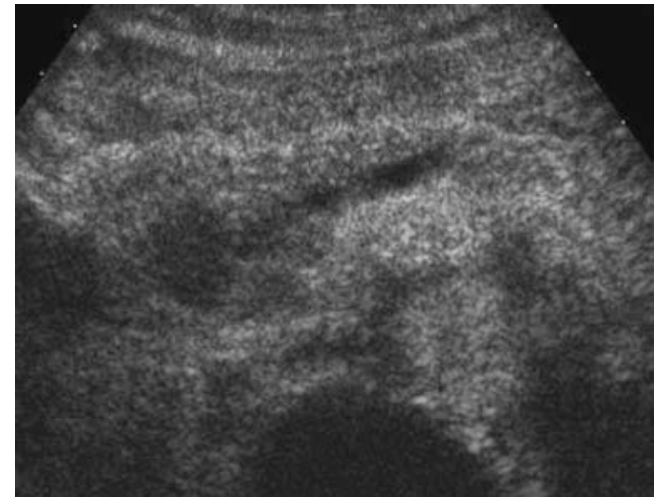

Figure 2 Pancreatic ductal adenocarcinoma. The pancreatic head solid lesion is hypoechoic in CEUS with upstream dilation of the main pancreatic duct.

tive ill-defined growth margins, typically hypoechoic in conventional US. The main pancreatic duct is usually infiltrated and dilated upstream. Doppler studies show poor or no vascularity inside the lesion and the vascular invasion is defined by a focal absence of the echogenic interface of the vessel wall, or by a narrow lumen, with changes in blood flow velocity ${ }^{[25-27]}$. In CEUS examination, ductal adenocarcinoma typically shows poor enhancement (Figure 2) during all the dynamic phases because of its intense desmoplastic reaction with a relatively poor mean vascular density and perfusion ${ }^{[5,6,23]}$. The degree of differentiation of the lesion influences its microvascular density ${ }^{[28]}$ : markedly hypovascular masses with very low mean vascular density and perfusion, characterized by avascular areas due to the presence of necrosis, correspond to highly aggressive forms, un-differentiated at pathology, with the poorest prognosis ${ }^{[10]}$.

Loco-regional US staging of ductal adenocarcinoma is very accurate ${ }^{[20]}$ and after the administration of microbubbles both margins and size of the lesion are more visible, improving the detection of vascular infiltration or involvement. In addition, CEUS improves hepatic staging, allowing a higher accuracy in the detection and characterization of distant metastases ${ }^{[18]}$.

Endocrine tumors: Endocrine tumors arise from the neuroendocrine cells of the pancreas and may induce specific clinical syndrome related to the tumor-released hormones (clinically classified as functioning endocrine tumors), or aspecific symptoms resulting from the expansive growth and tumor size [clinically classified as nonfunctioning endocrine tumors (NFETs) ${ }^{[19,29]}$. In conventional US, they usually present as well-demarked homogeneous hypoechoic masses ${ }^{[30]}$.

Imaging differentiation with ductal adenocarcinoma is fundamental for determining the therapeutic strategy and prognosis ${ }^{[31]}$. The main pancreatic duct is usually not infiltrated. In Doppler examination, small vessels characterized by arterial flow within the lesion are often detected. However, Doppler "silence" does not exclude the diagnosis of an endocrine tumor owing to the possible small size of the tumor vascular network ${ }^{[15]}$.

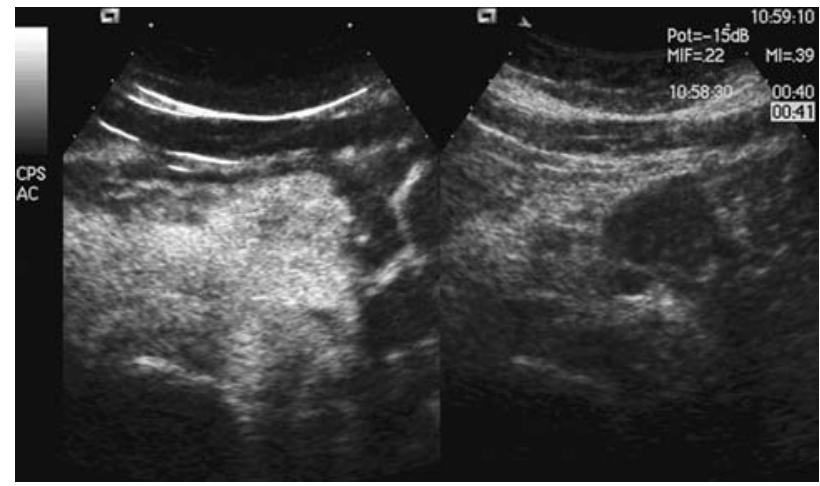

Figure 3 Pancreatic endocrine tumor. The pancreatic body mass is solid and hypoechoic in conventional US (right side of the split-screen) and hypervascular in CEUS (left side of the split-screen).

In CEUS, endocrine tumors usually appear hypervascular (Figure 3). Voluminous endocrine tumors show rapid and intense enhancement during the early dynamic phases, often with avascular necrotic intralesional areas ${ }^{[31-33]}$. Rarely, NFETs can also be hypovascularized in imaging, depending on the amount of dense and hyalinized stroma inside the lesion. CEUS improves local and hepatic staging, allowing a higher accuracy in the detection and characterization of distant metastases ${ }^{[15,34]}$.

Metastases: Pancreatic metastases are rare. The most common are from renal cell carcinoma. CEUS may well demonstrate the enhancement of pancreatic metastases from renal cell carcinoma, as they are clearly hypervascular, allowing differential diagnosis against ductal adenocarcinoma. However, their CEUS features cannot be differentiated from those of endocrine tumors. The differential diagnosis is therefore based on the clinical history and symptoms ${ }^{[35,36]}$

\section{Cystic neoplasms}

Serous cystadenoma: Serous cystadenoma (SCA) is a benign lesion ${ }^{[37]}$, usually solitary, without communication with the main pancreatic duct. Typically it presents as a microcystic well-defined lesion, macroscopically characterized by multiple small cysts separated by thin septa orientated to the center ${ }^{[19,38,39]}$. In $15 \%$ of cases a central scar may be present ${ }^{[38]}$. CEUS improves the US characterization of SCA, showing the enhancement of internal septa, with better identification of the "honeycomb" multilocular architecture of the lesion ${ }^{[17]}$. The macrocystic type $(25 \%)$ is divided into the mixed type with large cysts and the unilocular type difficult to be differentiated from $\mathrm{MCA}^{[40]}$. CEUS is helpful not only in the differential diagnosis of SCA, but also in the long-term followup of these tumors, which can be conservatively managed in most cases ${ }^{[3]}$.

Mucinous cystic tumors: Mucin-producing tumors of the pancreas may originate either from the peripheral ducts (mucinous cystic tumors) or from the main pan- 


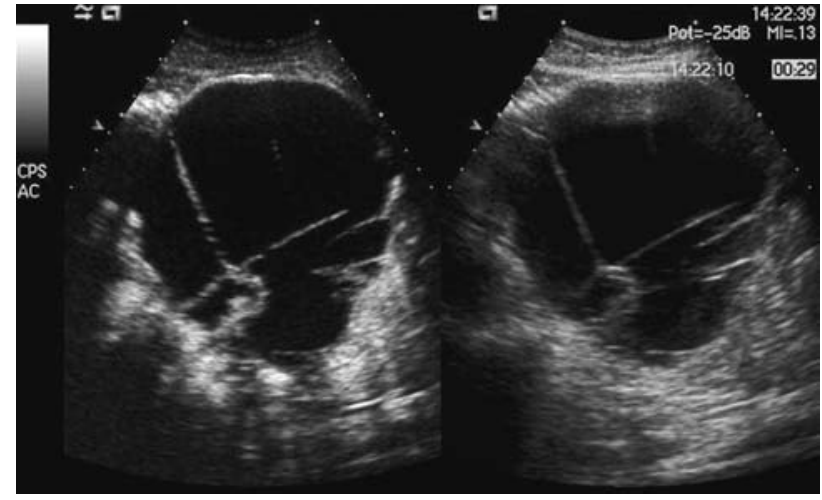

Figure 4 Pancreatic mucinous cystoadenocarcinoma. A voluminous cystic mass is seen in the pancreatic body with septa and nodules in conventional US (right side of the split-screen) and is enhanced in CEUS (left side of the splitscreen).

creatic duct and its collateral branches [intraductal papillary mucinous neoplasms (IPMNs) $]^{[41]}$.

MCA is a potentially malignant lesion ${ }^{[42]}$, which may degenerate into cystadenocarcinoma ${ }^{[37,39,43]}$. Imaging characterization is therefore mandatory for a correct therapeutic approach. MCA typically presents as a single round macrocystic lesion, usually located in the bodytail of the gland, without communication with the main pancreatic duct ${ }^{[44,45]}$. Often large and multilocular, but sometimes unilocular, in conventional US, it is characterized by a dense content resulting from the presence of mucin, and irregular thick wall and internal septa. The malignant degeneration into cystadenocarcinoma is usually characterized by the evidence of parietal nodules. The administration of contrast agent is necessary for a correct diagnosis, i.e. the identification of vascularized inclusions (Figure 4), and for the differential diagnosis between MCA and a pseudocyst ${ }^{[17,46]}$.

IPMNs are cystic tumors of the pancreas recently reported with increasing frequency ${ }^{[6,38,41,47,48]}$. They are macroscopically characterized by having an intraductal origin and growth ${ }^{[49]}$, with the production of dense mucin that fills the main pancreatic duct (the ductectatic mucin-hypersecreting variant) or with endoluminal papillary proliferation (the papillary-villous variant). The involvement or demonstration of communication with the main pancreatic duct is mandatory for a correct diagnosis ${ }^{[50,51]}$. They can be divided into 3 types: the central type, with focal or diffuse dilation of the main pancreatic duct; the side branch type, characterized by unilocular or multilocular cystic lesions with grapelike clusters; and the mixed type. US usually demonstrates dilatation of the main pancreatic duct, although MRI still remains the gold standard $^{[51]}$. CEUS study allows a better detection and characterization of intraductal papillary vegetation, especially in the papillary-villous variant, demonstrating their vascularization ${ }^{[17]}$, thus assisting in the differentiation between benign and malignant lesions ${ }^{[4]}$.

The presence of mural nodules, thick septa and a Wirsung's duct diameter greater than $10 \mathrm{~mm}$ are suggestive for malignancy ${ }^{[52]}$.
Solid-pseudopapillary tumor: A solid-pseudopapillary tumor (SPT) is a rare low-grade malignancy of the exocrine pancreas, typically presenting as a large well-defined round mass, without communication with the main pancreatic duct. In conventional US, it shows a inhomogeneous aspect because of hemorrhagic or necrotic or cystic degeneration ${ }^{[19,50]}$. After the administration of contrast agent, SPT typically shows inhomogeneous enhancement of the thickened peripheral capsule and solid components surrounding cystic and necrotic avascular areas.

\section{TEACHING POINTS}

Ultrasound is often the first examination performed in patients with suspicion of pancreatic pathology. In conventional US, the detection of a solid focal hypoechoic pancreatic mass should be considered a ductal adenocarcinoma. The greater accuracy of CEUS compared to conventional US can immediately result in better diagnostic workup and treatment planning. Any solid focal pancreatic mass hypo-enhancing to the normal parenchyma in CEUS has to be considered a ductal adenocarcinoma until otherwise proven. Endocrine tumors are the first differential diagnosis for any focal pancreatic mass hyper-enhancing to the normal parenchyma in CEUS. The presence of vascularized inclusions in a cystic lesion in CEUS excludes the diagnosis of pseudocyst, and the diagnosis of a cystic tumor must be considered. In the presence of any focal pancreatic mass iso-enhancing to the normal parenchyma in CEUS, fine needle aspiration cytology is mandatory for treatment planning.

\section{CONCLUSION}

CEUS has improved the characterization of pancreatic tumors, firstly differentiating between solid and cystic lesions. CEUS should always be performed immediately as a complementary imaging method to better characterize a pancreatic lesion detected in conventional US, saving time (faster diagnosis especially for ductal adenocarcinoma) and money (move directly to MRI for cystic tumors).

\section{REFERENCES}

1 Claudon M, Cosgrove D, Albrecht T, Bolondi L, Bosio M, Calliada F, Correas JM, Darge K, Dietrich C, D'Onofrio M, Evans DH, Filice C, Greiner L, Jäger K, Jong N, Leen E, Lencioni R, Lindsell D, Martegani A, Meairs S, Nolsøe C, Piscaglia F, Ricci P, Seidel G, Skjoldbye B, Solbiati L, Thorelius L, Tranquart F, Weskott HP, Whittingham T. Guidelines and good clinical practice recommendations for contrast enhanced ultrasound (CEUS) - update 2008. Ultraschall Med 2008; 29: 28-44

2 D'Onofrio M, Zamboni G, Faccioli N, Capelli P, Pozzi Mucelli R. Ultrasonography of the pancreas. 4. Contrastenhanced imaging. Abdom Imaging 2007; 32: 171-181

3 D'Onofrio M, Megibow AJ, Faccioli N, Malagò R, Capelli P, Falconi M, Mucelli RP. Comparison of contrast-enhanced sonography and MRI in displaying anatomic features of 
cystic pancreatic masses. AJR Am J Roentgenol 2007; 189: 1435-1442

4 Itoh T, Hirooka Y, Itoh A, Hashimoto S, Kawashima H, Hara K, Kanamori A, Ohmiya N, Niwa Y, Goto H. Usefulness of contrast-enhanced transabdominal ultrasonography in the diagnosis of intraductal papillary mucinous tumors of the pancreas. Am J Gastroenterol 2005; 100: 144-152

5 Oshikawa O, Tanaka S, Ioka T, Nakaizumi A, Hamada Y, Mitani T. Dynamic sonography of pancreatic tumors: comparison with dynamic CT. AJR Am J Roentgenol 2002; 178: 1133-1137

6 Ozawa Y, Numata K, Tanaka K, Ueno N, Kiba T, Hara K, Morimoto M, Sakaguchi T, Sekihara H, Kubota T, Shimada $\mathrm{H}$, Nakatani Y. Contrast-enhanced sonography of small pancreatic mass lesions. J Ultrasound Med 2002; 21: 983-991

7 Takeda K, Goto H, Hirooka Y, Itoh A, Hashimoto S, Niwa $\mathrm{K}$, Hayakawa T. Contrast-enhanced transabdominal ultrasonography in the diagnosis of pancreatic mass lesions. Acta Radiol 2003; 44: 103-106

8 Kersting S, Konopke R, Kersting F, Volk A, Distler M, Bergert $\mathrm{H}$, Saeger HD, Grützmann R, Bunk A. Quantitative perfusion analysis of transabdominal contrast-enhanced ultrasonography of pancreatic masses and carcinomas. Gastroenterology 2009; 137: 1903-1911

9 D'Onofrio M, Malagò R, Zamboni G, Vasori S, Falconi M, Capelli P, Mansueto G. Contrast-enhanced ultrasonography better identifies pancreatic tumor vascularization than helical CT. Pancreatology 2005; 5: 398-402

10 D'Onofrio M, Zamboni GA, Malagò R, Mantovani W, Principe F, Gallotti A, Faccioli N, Falconi M, Capelli P, Mucelli RP. Resectable pancreatic adenocarcinoma: is the enhancement pattern at contrast-enhanced ultrasonography a preoperative prognostic factor? Ultrasound Med Biol 2009; 35: 1929-1937

11 Tawada K, Yamaguchi T, Kobayashi A, Ishihara T, Sudo K, Nakamura K, Hara T, Denda T, Matsuyama M, Yokosuka O. Changes in tumor vascularity depicted by contrast-enhanced ultrasonography as a predictor of chemotherapeutic effect in patients with unresectable pancreatic cancer. Pancreas 2009; 38: $30-35$

12 Masaki T, Ohkawa S, Amano A, Ueno M, Miyakawa K, Tarao K. Noninvasive assessment of tumor vascularity by contrast-enhanced ultrasonography and the prognosis of patients with nonresectable pancreatic carcinoma. Cancer 2005; 103: 1026-1035

13 Kobayashi A, Yamaguchi T, Ishihara T, Tadenuma H, Nakamura K, Saisho H. Evaluation of vascular signal in pancreatic ductal carcinoma using contrast enhanced ultrasonography: effect of systemic chemotherapy. Gut 2005; 54: 1047

14 Faccioli N, D'Onofrio M, Comai A, Cugini C. Contrastenhanced ultrasonography in the characterization of benign focal liver lesions: activity-based cost analysis. Radiol Med 2007; 112: 810-820

15 D'Onofrio M, Mansueto G, Falconi M, Procacci C. Neuroendocrine pancreatic tumor: value of contrast enhanced ultrasonography. Abdom Imaging 2004; 29: 246-258

16 Lorén I, Lasson A, Fork T, Genell S, Nilsson A, Nilsson P, Nirhov N. New sonographic imaging observations in focal pancreatitis. Eur Radiol 1999; 9: 862-867

17 D'Onofrio M, Zamboni G, Malagò R, Martone E, Falconi M, Capelli P, Mansueto G. Pancreatic pathology. In: Quaia E, editor. Contrast media in ultrasonography. Berlin: SpringerVerlag, 2005: 335-347

18 Faccioli N, Crippa S, Bassi C, D'Onofrio M. Contrast-enhanced ultrasonography of the pancreas. Pancreatology 2009; 9: $560-566$

19 Procacci C, Biasiutti C, Carbognin G, Capelli P, El-Dalati G, Falconi M, Misiani G, Ghirardi C, Zamboni G. Pancreatic neoplasms and tumor-like conditions. Eur Radiol 2001; 11 Suppl 2: S167-S192
20 Kim T, Murakami T, Takamura M, Hori M, Takahashi S, Nakamori S, Sakon M, Tanji Y, Wakasa K, Nakamura H. Pancreatic mass due to chronic pancreatitis: correlation of $\mathrm{CT}$ and MR imaging features with pathologic findings. AJR Am J Roentgenol 2001; 177: 367-371

21 D'Onofrio M, Zamboni G, Tognolini A, Malago R, Faccioli N, Frulloni L, Pozzi Mucelli R. Mass-forming pancreatitis: value of contrast-enhanced ultrasonography. World J Gastroenterol 2006; 12: 4181-4184

22 Furukawa N, Muranaka T, Yasumori K, Matsubayashi R, Hayashida K, Arita Y. Autoimmune pancreatitis: radiologic findings in three histologically proven cases. J Comput Assist Tomogr 1998; 22: 880-883

23 Numata K, Ozawa Y, Kobayashi N, Kubota T, Akinori N, Nakatani Y, Sugimori K, Imada T, Tanaka K. Contrastenhanced sonography of autoimmune pancreatitis: comparison with pathologic findings. J Ultrasound Med 2004; 23: 199-206

24 Klöppel G, Schlüter E. Pathology of the pancreas. In: Baert AL, Delorme G, Van Hoe L, editors. Radiology of the pancreas. 2nd ed. Berlin: Springer-Verlag, 1999: 69-100

25 Bertolotto M, D'Onofrio M, Martone E, Malagò R, Pozzi Mucelli R. Ultrasonography of the pancreas. 3. Doppler imaging. Abdom Imaging 2007; 32: 161-170

26 Koito K, Namieno T, Nagakawa T, Hirokawa N, Ichimura T, Syonai T, Yama N, Someya M, Nakata K, Sakata K, Hareyama M. Pancreas: imaging diagnosis with color/power Doppler ultrasonography, endoscopic ultrasonography, and intraductal ultrasonography. Eur J Radiol 2001; 38: 94-104

27 Ueno N, Tomiyama T, Tano S, Wada S, Miyata T. Color Doppler ultrasonography in the diagnosis of portal vein invasion in patients with pancreatic cancer. J Ultrasound Med 1997; 16: 825-830

28 Numata K, Ozawa Y, Kobayashi N, Kubota T, Shimada H, Nozawa A, Nakatani Y, Sugimori K, Matsuo K, Imada T, Tanaka K. Contrast-enhanced sonography of pancreatic carcinoma: correlations with pathological findings. J Gastroenterol 2005; 40: 631-640

29 Fischer L, Kleeff J, Esposito I, Hinz U, Zimmermann A, Friess $\mathrm{H}$, Büchler MW. Clinical outcome and long-term survival in 118 consecutive patients with neuroendocrine tumours of the pancreas. Br J Surg 2008; 95: 627-635

30 Dixon E, Pasieka JL. Functioning and nonfunctioning neuroendocrine tumors of the pancreas. Curr Opin Oncol 2007; 19: $30-35$

31 Procacci C, Carbognin G, Accordini S, Biasiutti C, Bicego E, Romano L, Guarise A, Minniti S, Pagnotta N, Falconi M. Nonfunctioning endocrine tumors of the pancreas: possibilities of spiral CT characterization. Eur Radiol 2001; 11: 1175-1183

32 Minniti S, Bruno C, Biasiutti C, Tonel D, Falzone A, Falconi $M$, Procacci C. Sonography versus helical CT in identification and staging of pancreatic ductal adenocarcinoma. J Clin Ultrasound 2003; 31: 175-182

33 Solbiati L, Tonolini M, Cova L, Goldberg SN. The role of contrast-enhanced ultrasound in the detection of focal liver leasions. Eur Radiol 2001; 11 Suppl 3: E15-E26

34 D'Onofrio M, Mansueto G, Vasori S, Falconi M, Procacci C. Contrast-enhanced ultrasonographic detection of small pancreatic insulinoma. J Ultrasound Med 2003; 22: 413-417

35 Flath B, Rickes S, Schweigert M, Lochs H, Possinger K, Wermke W. Differentiation of a pancreatic metastasis of a renal cell carcinoma from a primary pancreatic carcinoma by echo-enhanced power Doppler sonography. Pancreatology 2003; 3: 349-351

36 Megibow AJ. Secondary pancreatic tumors: imaging. In: Procacci C, Megibow A, editors. Imaging of the pancreas: cystic and rare tumors. Berlin: Springer-Verlag, 2003: 277-288

37 Compagno J, Oertel JE. Microcystic adenomas of the pancreas (glycogen-rich cystadenomas): a clinicopathologic 
study of 34 cases. Am J Clin Pathol 1978; 69: 289-298

38 Procacci C, Biasiutti C, Carbognin G, Accordini S, Bicego E, Guarise A, Spoto E, Andreis IA, De Marco R, Megibow AJ. Characterization of cystic tumors of the pancreas: CT accuracy. J Comput Assist Tomogr 1999; 23: 906-912

39 Procacci C, Carbognin G, Biasiutti C, Ghilardi C, Misiani G, Schenal G, Tapparelli M. [Serous cystadenoma of the pancreas: imaging findings] Radiol Med 2001; 102: 23-31

40 Khurana B, Mortele KJ, Glickman J, Silverman SG, Ros PR. Macrocystic serous adenoma of the pancreas: radiologicpathologic correlation. AJR Am J Roentgenol 2003; 181: 119-123

41 Procacci C, Graziani R, Bicego E, Bergamo-Andreis IA, Mainardi P, Zamboni G, Pederzoli P, Cavallini G, Valdo M, Pistolesi GF. Intraductal mucin-producing tumors of the pancreas: imaging findings. Radiology 1996; 198: 249-257

42 Hammond N, Miller FH, Sica GT, Gore RM. Imaging of cystic diseases of the pancreas. Radiol Clin North Am 2002; 40: 1243-1262

43 Cohen-Scali F, Vilgrain V, Brancatelli G, Hammel P, Vullierme MP, Sauvanet A, Menu Y. Discrimination of unilocular macrocystic serous cystadenoma from pancreatic pseudocyst and mucinous cystadenoma with CT: initial observations. Radiology 2003; 228: 727-733

44 Buetow PC, Rao P, Thompson LD. From the Archives of the AFIP. Mucinous cystic neoplasms of the pancreas: radiologic-pathologic correlation. Radiographics 1998; 18: 433-449

45 Fugazzola C, Procacci C, Bergamo Andreis IA, Iacono C, Portuese A, Dompieri P, Laveneziana S, Zampieri PG, Jannucci A, Serio G. Cystic tumors of the pancreas: evaluation by ultrasonography and computed tomography. Gastrointest Radiol 1991; 16: 53-61

46 D'Onofrio M, Caffarri S, Zamboni G, Falconi M, Mansueto G. Contrast-enhanced ultrasonography in the characterization of pancreatic mucinous cystadenoma. J Ultrasound Med 2004; 23: 1125-1129

47 Procacci C, Megibow AJ, Carbognin G, Guarise A, Spoto E, Biasiutti C, Pistolesi GF. Intraductal papillary mucinous tumor of the pancreas: a pictorial essay. Radiographics 1999; 19: 1447-1463

48 Procacci C, Carbognin G, Biasiutti C, Guarise A, Ghirardi C, Schenal G. Intraductal papillary mucinous tumors of the pancreas: spectrum of CT and MR findings with pathologic correlation. Eur Radiol 2001; 11: 1939-1951

49 Zamboni G, Capelli P, Pesci A, Brighenti A. Pathology of cystic tumor. In: Procacci C, Megibow A, editors. Imaging of the pancreas: cystic and rare tumors. Berlin: SpringerVerlag, 2003: 85-94

50 Lewin M, Hoeffel C, Azizi L, Lacombe C, Monnier-Cholley L, Raynal M, Arrivé L, Tubiana JM. [Imaging of incidental cystic lesions of the pancreas] J Radiol 2008; 89: 197-207

51 Fukukura Y, Fujiyoshi F, Sasaki M, Inoue H, Yonezawa S, Nakajo M. Intraductal papillary mucinous tumors of the pancreas: thin-section helical CT findings. AJR Am J Roentgenol 2000; 174: 441-447

52 Sahani DV, Kadavigere R, Blake M, Fernandez-Del Castillo C, Lauwers GY, Hahn PF. Intraductal papillary mucinous neoplasm of pancreas: multi-detector row $\mathrm{CT}$ with 2D curved reformations--correlation with MRCP. Radiology 2006; 238: 560-569

S- Editor Cheng JX L- Editor Cant MR E- Editor Zheng XM 